
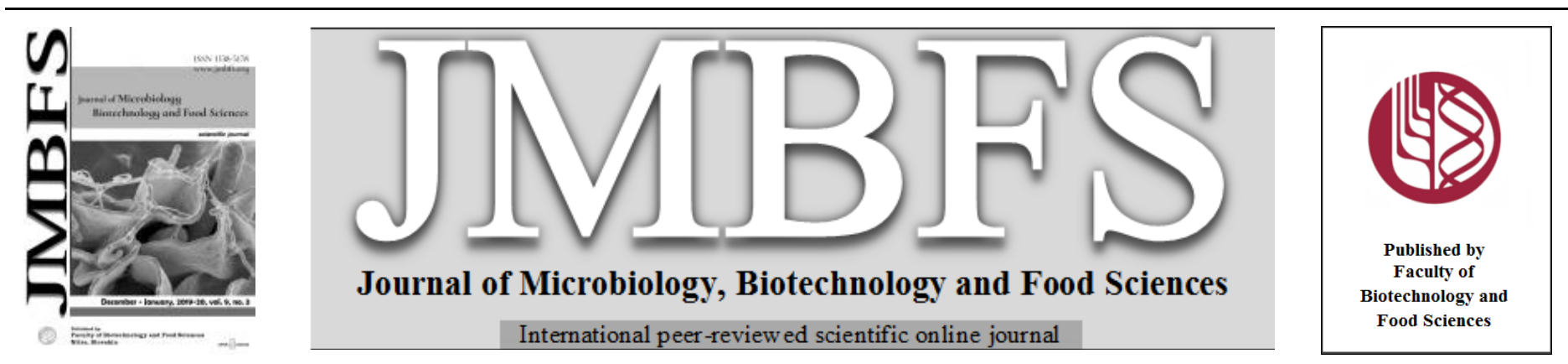

\title{
NEW MONOCLONAL ANTIBODIES TO THE PROSTATE-SPECIFIC ANTIGEN: OBTAINING AND STUDYING BIOLOGICAL PROPERTIES
}

\author{
Alexander Galkin ${ }^{1,2 *}$, Anatolii Komar ${ }^{1,3}$, Yuri Gorshunov ${ }^{4}$, Alexander Besarab ${ }^{1}$, Valentine Soloviova ${ }^{5}$
}

Address(es): Prof. Alexander Galkin,

${ }^{1}$ National Technical University of Ukraine "Igor Sikorsky Kyiv Polytechnic Institute”, Department of Translational Medical Bioengineering, Peremohy av., 37, 03056 Kyiv, Ukraine, Phone +380442048574 .

${ }^{2}$ Palladin Institute of Biochemistry of the National Academy of Science of Ukraine, Department of Molecular Immunology, Leontovich str., 9, 01601 Kyiv, Ukraine, Phone +380442345974 .

${ }^{3}$ Ukrainian medical certification centre of the Ministry of Health of Ukraine, Department of Conformity Assessment, Product Certification and Quality Management Systems, Chigorin str., 18, 01042 Kyiv, Ukraine, Phone +380442858383.

${ }^{4}$ Research and Design-Technological Institute of Municipal Economy, Urytsky str., 35, 03035 Kyiv, Ukraine, Phone +380442482339.

${ }^{5}$ State Research Center for Food Hygiene of the Ministry of Health of Ukraine, Chigorin str., 18, 01042 Kyiv, Ukraine, Phone +380442848875 .

*Corresponding author: a.galkin@kpi.ua

doi: 10.15414/jmbfs.2019/20.9.3.573-577

\section{ARTICLE INFO}

Received 21. 1. 2019

Revised 5. 6. 2019

Accepted 6. 6. 2019

Published 1. 12. 2019

Regular article OPEN $\partial_{\text {ACCESS }}$

\begin{abstract}
Original set of 15 clones of hybridomas producers of monoclonal antibodies (mAbs) to prostate-specific antigen (PSA) (using as a source of lymphocytes of mice of inbred strains NZB and Balb/c) was obtained. The activity in ELISA, affinity constant and titer in the culture fluid of the mAbs obtained from NZB mice are higher compared to the mAbs obtained from the Balb/c mice splenocytes. Conjugates of obtained mAbs with horseradish peroxidase were synthesized, and it allowed performing comparative epitope characterization of the resulting set of mAbs. Studied mAbs are directed to 4 epitopes of PSA molecule: 2 mAbs interacting with one of the epitopes showed cross-activity with PSA-related protein - human kallikrein 2; $2 \mathrm{mAbs}$ of the same epitope specificity blocked the enzymatic activity of PSA; mAbs of the remaining two epitopes either did not affect PSA chymotrypsin activity at all, or this inhibitory effect was not significant. The obtained mAbs recognize antigenic determinants that are not screened when interacting with $\alpha_{1-}$ antichymotrypsin, as well as those that are localized in the places where $\alpha_{1}$-antichymotrypsin interacts with PSA. Within each of the given two mAbs groups, there are antibodies belonging to different epitopes, which give prospects for the further use of the obtained mAbs in immunoassay and immunobiotechnology. Two alternative methods for determining of the mAbs constants of affinity (by Friguet and Scatchard) are comparable (for determination of the affinity constants of anti-PSA antibodies): coefficient of linear correlation between the affinity constants defined by different methods was 0.90 .
\end{abstract}

Keywords: monoclonal antibodies, prostate-specific antigen, affinity, epitopne mapping

\section{INTRODUCTION}

The Prostate-specific antigen (PSA), also known as gamma-seminoprotein or callicrein-3 (kallikrein 3, KLK3), is a glycoprotein enzyme with a molecular weight of $34 \mathrm{kDa}$, containing 237 amino acid residues, is related to serine proteinases (EC 3.4.21.77). PSA is encoded in humans by the $K L K 3$ gene, which is localized on the 19th chromosome (19q13). PSA in the sperm splits semenogelins present in the seminal coagulum. The total level of PSA is increased in serum in patients with prostatitis, benign hyperplasia and prostate cancer (PC). PSA is a biomarker for PC risk assessment. Serum protease inhibitors such as $\alpha_{1}$-antihymortitpsin (ACT), $\alpha_{2}$-macroglobulin (MG) and other acute-protein proteins form irreversible complexes with circulating PSA and inhibit its proteolytic activity (Fletcher, 2019; Duskova and Vesely, 2015; Haythorn and Ablin, 2011; Sydyakina et al., 2019).

Study of the PSA structure and its biological activity, as well as developments in the field of immune biotechnology, sometimes require the bioreagents antibodies that are specific to PSA. In this case, the most appropriate is the use of mAbs, since they, unlike polyclonal serums, are characterized by their exceptional specificity and homogeneity, as well as the possibility of obtaining virtually unlimited quantities. The identity of the mAbs' isotype and idiotype from batch to batch ensures reproducibility of their quality, and hence ensures the reproducibility of analytical techniques (Nikolaenko et al., 2005). One of the important elements of hybridoma technology is the use of effective immunization schemes that would ensure obtaining a broad or narrow-line epitopic repertoire of monoclonal antibodies (mAbs) with high affinity and activity in different immunoassay methods.
There are a number of works on the production of mAbs to PSA and/or the study of its antigenic or crystalline structure using anti-PSA mAbs (Bayat et al., 2015; Leinonen and Stenman, 2002; Ménez et al., 2008; Michel et al., 1999; Nurmikko et al., 2000; Piironen et al., 1998). Often not all the details of immunization are describing in mentioned works, but only Balb/c mice were used for anti-PSA mAbs production. Our previous work has shown the effectiveness of using alternative immunization schemes when using different mice inbred strains (NZB, Balb/c) (Galkin et al., 2019). To investigate the epitope specificity of described by other authors mAbs, mainly the phage display method was used which allows to determine the amino acid sequence of each antigenic determinant. An alternative method of studying the antigenic structure of biomolecules, which allows realizing applied tasks in the field of immunology and biotechnology, is the method of comparative epitope mapping based on the competition of various mAbs specific to a given antigen (Galkin et al., 2013). An important advantage of this method is its applicability to the study of antigens of various natures, as well as the ability to identify both linear and conformational antigenic determinants.

The aim of the work was to obtain new mouse monoclonal antibodies to the prostate-specific antigen, to study their biological properties as well as to conduct comparative epitope mapping of PSA using the obtained antibodies.

\section{MATERIAL AND METHODS}

\section{Immunization protocol}

The immunization protocol was justified and developed earlier (Galkin $\boldsymbol{e t}$ al., 2019). For immunization, NZB and Balb/c mice were used; females aged 6-8 
months. Animals were kept in cages under natural light, at a temperature of 20-22 ${ }^{\circ} \mathrm{C}$; access to water and food was free. Studies with animals were carried out in compliance with bioethical standards (European Convention for the protection of vertebrate animals used for experimental and other scientific purposes). The prostate-specific antigen isolated from human sperm (Sigma, USA) was used as an immunogen (in form of a buffer aqueous solution with a purity of $99 \%$ by electrophoresis and protein concentration $0.5-0.6 \mathrm{mg} / \mathrm{ml}$. To prepare the solution for immunization, the PSA was diluted to the required concentration by saline solution.

The first immunization was performed with Freund's complete adjuvant (FCA), and the other injections - with Freund's incomplete adjuvant (FIA). PSA solution in saline was used for booster (final) immunization. For consecutive intraperitoneal immunizations (on the $0,28^{\text {th }}, 42^{\text {nd }}, 56^{\text {th }}$ days), an emulsion of the immunogen solution was prepared with an adjuvant with a final dose of $10 \mu \mathrm{g}$ : $50 \mu \mathrm{l}$ of the PSA solution was dissolved in saline, a similar amount of adjuvan was added and thoroughly mixed until a stable emulsion was formed. The booster immunization on the $60^{\text {th }}$ day $(10 \mu \mathrm{g}$ per $100 \mu \mathrm{l})$ was performed in the tail vein of mice. On the $4^{\text {th }}$ day after the last injection of PSA, the spleen cells of mice were hybridized with $\mathrm{Sp}$ 2/0 myeloma cells.

\section{Hybridomas and mAbs obtaining}

The fusion was made using polyethylene glycol $\mathrm{M}_{\mathrm{r}}$ 3500-3700 (Sigma, USA) according to Kohler and Milstein, 1975, approach modified by Lane and Koprowski, 1982. The hybridomal clones obtained were multiplied on peritonea macrophage feeder cells in a complete growth medium H-Y (Sigma, USA) supplemented with calf embryo serum (Sigma, USA) and HAT medium (Sigma USA). The cells were cultivated in 96-welled plates for tissue cultures (Costar, USA).

The presence of anti-PSA mAbs in hybridomal growth media was controlled by an indirect ELISA approach on the $10^{\text {th }}-12^{\text {th }}$ day of cultivation. Following experiment, the optical density values of supernatant fluids of mAbs-positive cultures were by 2-3 times higher comparing to the conjugate. Cells from appropriate wells were taken into 24 -welled plates with peritoneal macrophage feeder cells in the complete growth medium supplemented with the HT medium (Sigma, USA). The cells obtained were frozen in a medium containing newborn calf serum (50\%, Sigma, USA), DMEM medium (43\%, Sigma, USA), and dimethylsulfoxide ( $7 \%$, Sigma, USA). The aliquots of culture fluids were used to determine the mAbs specificity, their titers and affinity constants as well as their isotypes. The chosen hybridomal clones were then thawed and cloned several times to reach stabile levels of antibody synthesis. The cloning was carried out using the end-point dilution method; the hybridomal cells were grown on peritoneal macrophage feeder cells in the complete growth medium. The screening of hybridomal cells was realized by the indirect enzyme-linked immunosorbent assay (ELISA). Hybridomal cells with stabile antibody production were multiplied and injected to mice in order to obtain ascite fluids, the mice having been previously primed by pristane (Sigma, USA). Purification of mAbs from ascite fluids was carried out by a double precipitation protocol using $18 \%$ and $16 \% \mathrm{Na}_{2} \mathrm{SO}_{4}(\mathrm{w} / \mathrm{v})$.

\section{Indirect ELISA}

Indirect ELISA modification was used for hybridoma clones screening and determining of mAbs' specificity. Polystyrene 96-well plates (Suzhou Conrem Biomedical Technology Co., China) were coated with $100 \mu \mathrm{lof} 1 \mathrm{mg} / \mathrm{l} \mathrm{PSA}$ in $0.05 \mathrm{M}$ carbonate-bicarbonate buffer $(\mathrm{pH} 9.6), 4{ }^{\circ} \mathrm{C}$. For plates washing a phosphate-buffered saline with the Tween $20(0.05 \%)$ (PBS-T, pH 7.2) was used The plates were incubated with studied samples $(100 \mu \mathrm{l})$ for $1 \mathrm{~h}\left(37^{\circ} \mathrm{C}\right)$ and then washed three times. To detect the bounded antibodies, goat anti-mouse immunoglobulins conjugated with horseradish peroxidase (HRP) were used (incubation for $1 \mathrm{~h}$ at room temperature). $0.003 \%$ hydrogen peroxide in $0.15 \mathrm{M}$ citrate buffer ( $\mathrm{pH}$ 5.0) was used as substrate, and 3,3',5,5'-tetramethylbenzidine was a chromogen. The reaction was stopped by $2 \mathrm{M}$ sulfuric acid $(100 \mu \mathrm{l})$ in 30 min. The absorbance was measured at $450 \mathrm{~nm}$ with ELISA plate reader.

\section{Competitive ELISA}

Competitive ELISA modification was used for mAbs epotipe mapping. PSA sorption was carried out as for indirect ELISA. Conjugated mAbs of each clone were incubated together with different dilutions of another mAbs (starting from $0.4 \mathrm{mg} / \mathrm{ml}$, and ending $6.25 \mu \mathrm{g} / \mathrm{ml}$ ). As a control, we used the absorbance in wells where certain $\mathrm{mAb}$ conjugate competes with eponymous mAbs. The further procedure was carried out similarly to indirect ELISA.

\section{Evaluation of mAbs affinity}

The first method was as follows. The mAbs' affinity constants were evaluated according to the inhibition method proposed by Friguet $\boldsymbol{e t}$ al., 1985, modified by Kim et al., 1990. Affinity constants were calculated by Bobrovnik et al., 2010, recommendation. The mAbs supernatants with different PSA concentrations $(10$ $\left.{ }^{9}-10^{-6} \mathrm{~mol} / \mathrm{l}\right)$ were mixed with mAbs-containing culture fluid samples. Following incubation $\left(1 \mathrm{~h}\right.$ at $\left.37^{\circ} \mathrm{C}\right)$ the mixtures were put into 96 -welled plate wells sensitized previously by PSA preparation and the ELISA performance was carried out. Control plate wells contained culture fluid samples non-incubated with the PSA preparation.

The second method (Scatchard, 1949, proposed) was as follows. PSA sorption was carried out as for indirect ELISA. PSA solutions $\left(100 \mu \mathrm{l}, 10^{-11}-10^{-8} \mathrm{~mol} / \mathrm{l}\right)$ were incubated for $1 \mathrm{~h}$ at $37^{\circ} \mathrm{C}$, and then unbound PSA concentration were defined by commercial ELISA kit "TotalPSA-ELISA" (Chema, Ukraine). PSA concentrations were calculated by means of calibration chart. The values of affinity constants were calculated as tangents of the angle of straight lines in the corresponding coordinates.

\section{Determination of mAbs isotype}

The isotype determination of the obtained mAbs was made using a standard kit ISO-2 (Sigma, USA). The isotyping was carried out by antigen-mediated ELISA Hybridomal culture fluids were put into the plate wells sensitized by $100 \mu \mathrm{l}$ of $\mathrm{mg} / \mathrm{l}$ PSA, each sample was put into six wells. The mAbs isotype was determined by a goat monospecific serum. The typing antibodies were detected by an antigoat HRP-containing conjugate (Sigma, USA). The results were read according to the manufacturer's recommendations.

\section{Determination of PSA chymotrypsin activity and its inhibition}

The PSA enzymatic activity was determined by hydrolysis of the substrate MeOSuc-Arg-Pro-Tyr-pNA $-\mathrm{HCl}$ (Biocompare, USA) at the final concentration of 5 $\mathrm{mmol} / \mathrm{l}$ in $50 \mathrm{mmol} / \mathrm{l}$ Tris- $\mathrm{HCl}, \mathrm{pH} 7.8,0.1 \mathrm{~mol} / \mathrm{l} \mathrm{NaCl}$ (Christensson et al. 1990). Hydrolysis was measured at $405 \mathrm{~nm}\left(\mathrm{~A}_{405}\right)$ in an ultraviolet recording spectrophotometer. All reactions were performed at $37^{\circ} \mathrm{C}$ and initiated by the addition of $5 \mathrm{mg}$ of PSA. The absorbance was monitored for $30 \mathrm{~min}$.

To determine the inhibition of PSA enzyme activity by different mAbs, a preliminary incubation of PSA with each mAbs (1 mol PSA per $1 \mathrm{~mol}$ of mAb) was performed; the final concentration of PSA and mAbs after substrate adding was $0.4 \mu \mathrm{mol} / 1$. As control, PSA in a reaction buffer without a substrate was used, as well as in each individual $\mathrm{mAb}$. For the convenience of evaluating the results, a change in $\mathrm{A}_{405}$ over the time $\left(\Delta \mathrm{A}_{405} / \mathrm{min} \times 1000\right)$ and percentage of inhibition compared with activity of native PSA were calculated (Michel $\boldsymbol{e t}$ al., 1999).

\section{Synthesis of HRP-containing conjugates}

The mAbs conjugation with the horseradish peroxidase was carried out according to periodate oxidation approach (Galkin et al., 2018) with some modifications, the mAb/enzyme mass ratio being $2: 1$. The HRP $(15 \mathrm{mg} / \mathrm{mL}, 150-250$ units $/ \mathrm{mg}$ solid, using pyrogallol; Sigma, USA) was diluted in the $0.1 \mathrm{M}$ bicarbonate buffer $(\mathrm{pH} 8.3)$ and mixed with an equal volume of the sodium periodate solution (14 $\mathrm{mM})$. For the HPR oxidation, the mixture was incubated for $2 \mathrm{~h}$ at room temperature. The solution of the oxidized HRP was mixed with an antibody solution which had been previously dialyzed against the 0.1 bicarbonate buffer $(\mathrm{pH}$ 9.2). This mixture was then put into a chromatographic column; dry Sephadex G-25 (Fluka, Switzerland) was added (1:3, v/v), and the mixture was incubated for $3 \mathrm{~h}$ at room temperature. The conjugate solution was eluted from the column; $1 / 20$ volume of the aqueous $\mathrm{NaBH}_{4}$ solution $(5 \mathrm{mg} / \mathrm{ml})$ was then added. To stop the reaction, the mixture was kept $30 \mathrm{~min}$ at room temperature; then additional portion of the $\mathrm{NaBH}_{4}$ solution $(3: 20$, v/v) was added, and the mixture was incubated for $60 \mathrm{~min}$. The obtained solution of a mAbs-HPR conjugate was dialyzed against $0.02 \mathrm{M}$ phosphate buffer containing $0.15 \mathrm{M} \mathrm{NaCl}$.

\section{RESULTS AND DISCUSSION}

\section{Obtaining and primary characterization of mAbs}

As a result of hybridization of both NZB and Balb/c mice' splenocytes about $500 \div 600$ clones were obtained (in each case). In the initial testing after hybridization, the specific antibodies to PSA were detected in all wells. Cultural fluids during the screening were diluted several times, which allowed to significantly reducing the background signal.

Thus, 39 clones that had the highest signals according to the results of indirect ELISA were selected ( 24 clones from Balb/c mice and 15 clones from NZB mice). All selected hybridomas were cryopreserved, and culture fluids were left for further study. After repeated testing in ELISA, high activity of the mAbs was confirmed in 17 clones (Table 1). In order to study the specificity of mAbs in the next step, the supernatants of the selected clones of the hybridomas were additionally tested for: complex of PSA with human $\alpha_{1}$-antichymotrypsin (ACT) and recombinant human kallikrein-2 (hK2). It should be noted that hybridomas supernatants testing for complex of PSA with $\alpha_{2}$-macroglobulin was inappropriate because PSA is completely encompassed in the $720-\mathrm{kDa}$ MG molecule. Analysis of the testing results allowed dividing the obtained mAbs into three groups of specificity: the $1^{\text {st }}$ group contains $8 \mathrm{mAbs}$ and characterize by 
positive signals on PSA only (11B5, 12F11, 13C2, 13G4, 14C8, 21D7, 23B4, 21B7); the $2^{\text {nd }}$ group contains $8 \mathrm{mAbs}$ and characterize by positive signals on PSA as well as on PSA-ACT complex (17F9, 12C7, 11G5, 21F4, 27C10, 26B9, $24 \mathrm{H} 7)$; and the $3^{\text {rd }}$ group is presented by $2 \mathrm{mAbs}$, which is positive on testing of all markers (PSA, PSA-ACT complex and hK2).

These results indicate three variants of group specificity of the obtained mAbs. The group I antibodies directed to PSA epitopes, which are screened when it binds to ACT (these mAbs can be used to detect free PSA, f-PSA). The group II antibodies, in contrast, are directed to PSA epitopes that are not screened when it binds to ACT (these antibodies are able to detect total PSA (t-PSA) in the blood serum: free molecules, as well as those associated with ACT). The group II antibodies are characterized by cross-reactivity with the related protein hK2. This is not surprising since homology of amino acid sequences of PSA and hK2 proteins is 79\% (Lundwall and Lilja, 1987; Schedlich et al., 1987).

Table 1 Characterization of anti-PSA mAbs

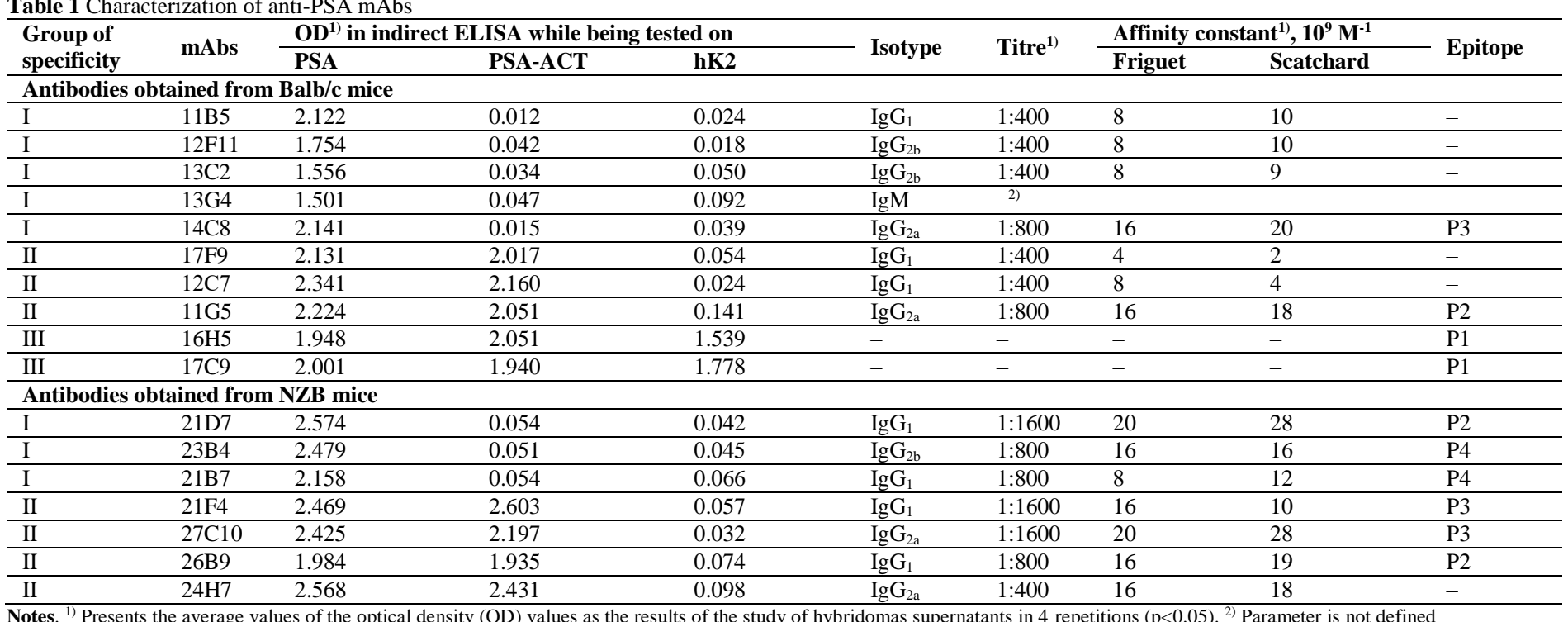

Notes. ${ }^{1)}$ Presents the average values of the optical density (OD) values as the results of the study of hybridomas supernatants in 4 repetitions $(\mathrm{p}<0.05) .{ }^{2)}$ Parameter is not defined

Comparison of the mAbs testing results (mAbs obtained from different inbred mice and different antigens) allowed establishing the following consistent pattern. As a result of both hybridizations, we have obtained mAbs targeting the antigenic determinants of both free PSA and total PSA. Thus, for the inbred strains mice Balb/c and NZB used in our work, a similar epitope profile of the immune response is observed. However, the mAbs obtained from the NZB mice splenocytes $\left(\mathrm{mAbs}_{\mathrm{NZB}}\right)$ were characterized by a more intense signal in the ELISA when tested on both PSA and its complex with ACT (figure 1). At the same time, no cross-activity with $\mathrm{hK} 2$ was detected among $\mathrm{mAbs}_{\mathrm{NZB}}$, however, this may be due to the prior exclusion of low-level mAbs in previous stages of work. Thus, it can be assumed that NZB mice immune response is more expressed to PSAspecific antigenic determinants.

Based on literary data and our previous experience (Miche et al., 1999; Nurmikko et al., 2000; Galkin et al., 2013; Bayat et al., 2015; Shtapenko et al., 2018), at the next stage we have performed an in-depth study of the mAbs' properties including the following characteristics: titer in the culture fluid, affinity and isotype. Characterization of the mAbs by the first two criteria (titer and affinity) made it possible to assess the prospects for the use of mAbs in immunoassay. The isotype of antibodies, on the one hand, affects the feasibility of it using in various bioanalytical methods, and on the other, is an important prerequisite for choosing the method for its isolation and purification. For example, protein A of Staphylococcus aureus can be used for efficient affinity purification of mouse antibodies of the $\operatorname{IgG}_{2 \mathrm{a}}, \mathrm{IgG}_{2 \mathrm{~b}}$ and $\mathrm{IgG}_{3}$ isotypes, and protein $\mathrm{G}$ also can be used in case of mouse antibodies of all isotypes, except IgM isotype (Goding, 1996). The titer, as well as the affinity constant (Friguet method), was determined for all mAbs, except for those that were characterized by the IgM isotype due to the non-technological conditions for subsequent purification (192D2, 196D4, 217C4), and for which cross-activity towards hK2 due to the futility of their further use in immunoassay $(16 \mathrm{H} 5,17 \mathrm{C} 9)$. All results are shown in table 1 .

All studied $\mathrm{mAb}$ were characterized by a fairly high titer $(\geq 1: 400)$, about a third of them ( 6 out of 17) had a titer $\geq 1: 800$. It should be noted that, in general, the mAbs' titers were correlated with the affinity constants value: mAbs with the highest titers were characterized by a high value of the affinity constant (for an mAbs with a titer $<1: 800$ the average value of Ka was $7.3 \times 10^{9} \mathrm{M}^{-1}$, while for a mAbs with a titer $\geq 1: 800$, the arithmetic average of Ka was $16.0 \times 10^{9} \mathrm{M}^{-1}$ ). When analyzing the average values of the titer and affinity constants of mAbs of different origin, the following was established. $\mathrm{mAbs}_{\mathrm{NZB}}$ (compared $\mathrm{mAbs} \mathrm{Baab} / \mathrm{c}_{\mathrm{B}}$ ) characterized by higher values of both the titers and affinity constants, so the average value of Ka for $\mathrm{mAbs}_{\mathrm{NZB}}$ was $14.9 \times 10^{9} \mathrm{M}^{-1}$, while for $\mathrm{mAbs}_{\text {Balb/c }} \mathrm{Ka}$ was only $9,7 \times 10^{9} \mathrm{M}^{-1}$.

The totality of the obtained data (the activity in ELISA, the isotype, the titer and affinity constant of the mAbs) was used by us for the selection of hybrid clones for their further defrosting, cloning, cultivating and accumulation of antibodies Preference was given to high titer clones $(\geq 1: 800)$ and affinity constant $\left(\geq 8.0 \times 10^{9}\right.$
$\left.\mathrm{M}^{-1}\right)$. Only 8 mAbs (14C8, 11G5, 21D7, 23B4, 21B7, 21F4, 27C10, and 26B9) met these criteria.

Cloning of hybridomas was performed by limiting dilutions technique. All clones were cloned 2 to 4 times - up to almost complete stability at the level of synthesis of specific mAbs. Isolated positive clones from a 96-well plate were transplanted into 24-well, hybridomas were grown, frozen and administered to the mice intraperitoneally. At 7-10 days the animals accumulated ascites, which were taken. One mouse gave up to $10 \mathrm{ml}$ of ascitic fluid on average. After isolation from ascitic fluid, mAbs was used for the synthesis of peroxidase conjugates that were needed to establish their epitope specificity, as well as mAbs' affinity determination by the alternative Scatchard method.

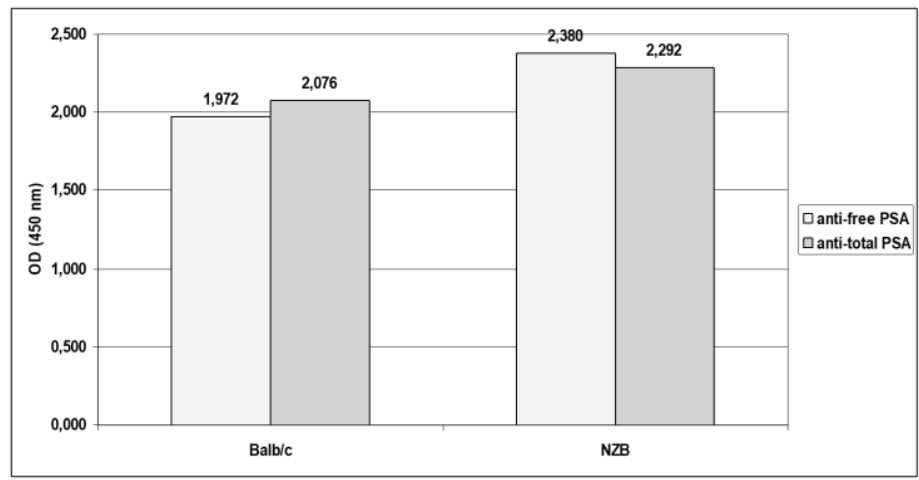

Figure 1 Comparative characteristics of the activity of the mAbs of different origin, directed to different groups of epitopes

\section{Inhibition of PSA enzymatic activity by mAbs}

For mAbs of groups' I and II a study of an inhibitory effect on the PSA enzymatic activity was contacted. As is well known, PSA is a serine protease of the chymotrypsin type, and this PSA enzymatic function in the human body is necessary for the dilution of the ejaculate. Chymotrypsin activity was determined through the amidolytic effect of PSA on the appropriate substrate (MeO-SucArg-Pro-Tyr-pNA). The results of these studies are shown in table 2. Thus, 4 of the obtained mAbs showed a pronounced inhibitory effect on PSA chymotrypsin activity (inhibition level is more than 90\%): three of them belong to the group I of specificity (anti-free PSA) $(13 \mathrm{C} 2,23 \mathrm{~B} 4,21 \mathrm{~B} 7)$ and one belongs to the group II of specificity (anti-total PSA) - 24H7. Obviously, antigenic determinants of these antibodies are localized directly in the region of the active center of PSA or in close proximity (in last case, interaction with the mAbs changes the conformation of the active center of PSA or screens it, thereby preventing substrate binding). About half of the studied mAbs (11B5, 12F11, 13G4, 14C8, 
$17 \mathrm{~F} 9,12 \mathrm{C} 7,21 \mathrm{~F} 4,27 \mathrm{C} 10)$ were characterized by an average level of inhibition and three mAbs (21D7, 11G5, 26B9) did not significantly affect the level of PSA enzymatic activity. At the same time, the majority of antibodies (12 out of 15 mAbs) in one way or another influenced the PSA chymotrypsin activity, which indicates quite significant changes in the PSA conformation when the mAbs interact with PSA molecule. It should be noted that similar results were obtained by other authors (Miche $\boldsymbol{e t}$ al., 1999), which refers both to the level of inhibition of the PSA enzymatic activity and to the ability to inhibit the formation of the PSA-ACT complex by various mAbs (both anti-free PSA and anti-total PSA).

Table 2 Inhibition of PSA enzymatic activity by anti-PSA mAbs

\begin{tabular}{|c|c|c|}
\hline Anti-PSA mAbs & $\Delta \mathbf{A}_{405} / \min \times \mathbf{1 0 0 0}$ & Inhibition, \% \\
\hline 11B5 & $11.23 \pm 0.16$ & 57.0 \\
\hline $12 \mathrm{~F} 11$ & $20.31 \pm 0.51$ & 22.3 \\
\hline $13 \mathrm{C} 2$ & $0.47 \pm 0.12$ & 98.2 \\
\hline $13 \mathrm{G} 4$ & $18.18 \pm 0.24$ & 30.5 \\
\hline $14 \mathrm{C} 8$ & $21.44 \pm 0.36$ & 18.0 \\
\hline 21D7 & $27.04 \pm 0.25$ & -3.4 \\
\hline $23 \mathrm{~B} 4$ & $1.98 \pm 0.10$ & 92.4 \\
\hline $21 \mathrm{~B} 7$ & $0.34 \pm 0.04$ & 98.7 \\
\hline $17 \mathrm{~F} 9$ & $18.07 \pm 0.08$ & 30.9 \\
\hline $12 \mathrm{C} 7$ & $19.34 \pm 0.26$ & 26.0 \\
\hline 11G5 & $26.18 \pm 0.41$ & -0.2 \\
\hline $21 \mathrm{~F} 4$ & $10.37 \pm 0.16$ & 60.3 \\
\hline $27 \mathrm{C} 10$ & $19.29 \pm 0.16$ & 26.2 \\
\hline $26 \mathrm{~B} 9$ & $25.20 \pm 0.16$ & 3.6 \\
\hline $24 \mathrm{H} 7$ & $0.27 \pm 0.04$ & 99.0 \\
\hline mAb control & $26.11 \pm 0.14$ & 0,1 \\
\hline PSA control & $26.14 \pm 0.06$ & 0,0 \\
\hline
\end{tabular}

Comparison of different methods for mAbs' affinity evaluation

The results of the affinity constants calculation by Scatchard method are given in table 1 , and the results of comparison of the affinity constants determined by various methods are shown in figure 2. To estimate of the correlation of the obtained values of the affinity coefficient, we used a linear correlation analysis, which allows establishing direct links between variables by their absolute values. As is known, the method of the correlation coefficient calculating is constructed in such a way that, if the relationship between the signs is linear, the Pearson coefficient (r) accurately determines the closeness of this relationship. In this case, the linear correlation coefficient between the two samples was 0.90 , which indicates a fairly high degree of correlation, so the Friguet and Scatchard methods can be considered comparable when determining the affinity of PSA specific antibodies.

Table 3 Comparative epitope characteristics of anti-PSA mAbs

Epitopes and mAbs

\begin{tabular}{|c|c|c|c|c|c|c|c|c|c|c|c|}
\hline \multirow{3}{*}{ Epitopes } & \multirow{3}{*}{$\mathrm{mAbs}$} & \multicolumn{10}{|c|}{ Epitopes and mAbs } \\
\hline & & \multicolumn{2}{|c|}{ P1 } & \multicolumn{2}{|l|}{$\mathbf{P 2}$} & \multicolumn{3}{|c|}{ P3 } & \multicolumn{3}{|c|}{ P4 } \\
\hline & & $16 \mathrm{H5}$ & 17C9 & 21D7 & $11 G 5$ & 26B9 & 21F4 & 14C8 & $27 \mathrm{C10}$ & 21B7 & 23B4 \\
\hline \multirow{2}{*}{ P1 } & $16 \mathrm{H5}$ & 1 & + & - & - & - & - & - & - & - & - \\
\hline & $17 \mathrm{C9}$ & 0.97 & 1 & - & - & - & - & - & - & - & - \\
\hline \multirow{3}{*}{ P2 } & 21D7 & 0.42 & 0.41 & 1 & + & + & \pm & - & - & - & - \\
\hline & $11 G 5$ & 0.45 & 0.35 & 0.97 & 1 & + & - & - & - & - & - \\
\hline & $26 B 9$ & 0.39 & 0.39 & 0.95 & 0.85 & 1 & - & - & \pm & - & - \\
\hline \multirow{3}{*}{ P3 } & $21 F 4$ & 0.15 & 0.11 & 0.48 & 0.32 & 0.21 & 1 & + & + & \pm & \pm \\
\hline & $14 C 8$ & 0.09 & 0.25 & 0.27 & 0.27 & 0.22 & 0.86 & 1 & + & \pm & \pm \\
\hline & $27 \mathrm{C} 10$ & 0.15 & 0.14 & 0.37 & 0.29 & 0.51 & 0.93 & 0.91 & 1 & \pm & \pm \\
\hline \multirow{2}{*}{ P4 } & 21B7 & 0.09 & 0.19 & 0.15 & 0.05 & 0.22 & 0.48 & 0.51 & 0.55 & 1 & + \\
\hline & 23B4 & 0.12 & 0.13 & 0.16 & 0.09 & 0.07 & 0.51 & 0.47 & 0.61 & 0.92 & 1 \\
\hline
\end{tabular}

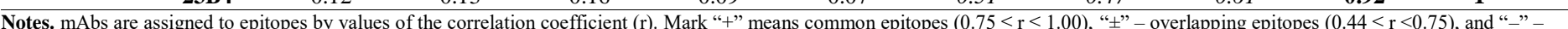
independent epitopes $(r<0.44)$.

A comparative mAbs epitope characterization showed that the antibodies were directed to four epitopes of the PSA molecule (it conventionally designated by us as $\mathrm{P} 1, \mathrm{P} 2, \mathrm{P} 3$, and $\mathrm{P} 4$ ) (table 1 and table 3 ). mAbs $16 \mathrm{H} 5$ and $17 \mathrm{C} 9$, cross-reacting with the hK2 molecule, interacted with the P1 epitope. Three mAbs (11G5, 21D7 and 26B9) interacted with the P2 epitope, and mAbs 14C8, 21F4 and 27C10 relate to the P3 epitope. Note that the mAbs of the P2 and P3 epitopes are derived from the lymphocytes of both used inbred mouse lines. The P4 epitope, in contrast, includes two mAbs 23B4 and 21B7, which were obtained from the NZB mice splenocytes. To assess the cross-reactivity between the mAbs of different epitopes, we calculated the arithmetic mean values of the correlation coefficients between different epitopes (figure 3). The largest $r$ values were for epitopes pair of P3-P4 ( $\mathrm{r}=0.52)$; a mAbs of this epitopon specificity either completely inhibited the enzymatic activity of PSA (mAbs of the P4 epitope), or markedly reduced the chymotrypsin activity when interacting with PSA (mAbs of the P3 epitope). Epitopes P3 and P4 are quite far from the P2 epitope (the r value for P2$\mathrm{P} 3$ and $\mathrm{P} 2-\mathrm{P} 4$ pairs is 0.33 and 0.12 , respectively); mAbs targeting the antigenic

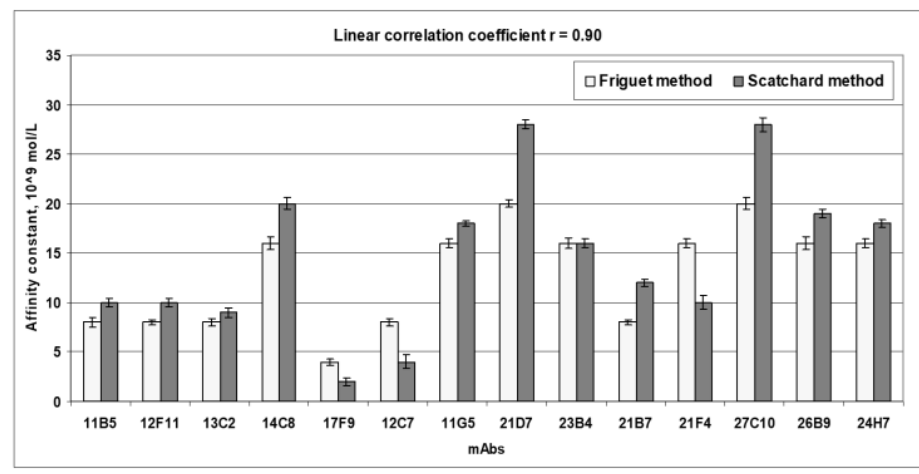

Figure 2 Comparison of the affinity constants of mAbs to PSA, determined by various methods

\section{Epitope characterization of anti-PSA mAbs}

Comparative epitope mapping, based on the competition of different mAbs, does not allow for the absolute localization of antigenic determinants, but it makes it possible to determine the number of immunodominant regions and/or epitopes, as well as their remoteness from each other. Such information is extremely important when conducting applied developments in immune biotechnology; in particular, it can significantly increase the specificity and sensitivity of immunochemical methods of analysis (Pokrovsky et al., 2016; Galkin et al. 2013).

Comparative epitope characterization of the mAbs was performed using competitive ELISA. The results of the competing effect were calculated as the percentage reduction in the activity of the mAbs' conjugate in the presence of a competing antibody. In this version of competitive ELISA, a complete or partial decrease in activity is an indicator of the complete or partial similarity of the epitope specificity of the studied mAbs. At the same time, mAbs conjugate activity which was comparable with the control indicated different epitope specificity with the competing antibody. For this study, 8 more active and affine mAbs, as well as $2 \mathrm{mAbs}$ of the $3^{\text {rd }}$ group of specificity (cross-reacting with hK2) were used. Thus, as a result of the studies for each $\mathrm{mAb}$, a comparative epitope profile was obtained from 9 variants of competition with other antibodies. To facilitate the analysis of such a large data set, the Brava-Pearson correlation analysis was used to compare profiles. The degree of similarity was expressed in terms of the profile correlation coefficient with its statistical significance $(\mathrm{p}<0.05)$. High values of positive correlation coefficients between profiles $(0.75 \leq \mathrm{r} \leq 1.00)$ were interpreted as evidence of the same epitope specificity, smaller values $(0.44 \leq \mathrm{r}<0.75)$ were considered an indicator of cross epitopes, and statistically insignificant coefficients $(r<0.44)$ were regarded as evidence of independent, completely different epitopes. determinant P2 did not have a significant effect on the enzymatic activity of PSA The hK2 cross-reacting mAbs recognized the P1 epitope that is closest to the P2 antigenic determinant ( $\mathrm{r}$ for the P1-P2 pair is 0.40 ) and is quite far from the P3 and P4 epitopes (the $r$ value for the P1-P3 and P1- P4 are 0.15 and 0.13 , respectively). 


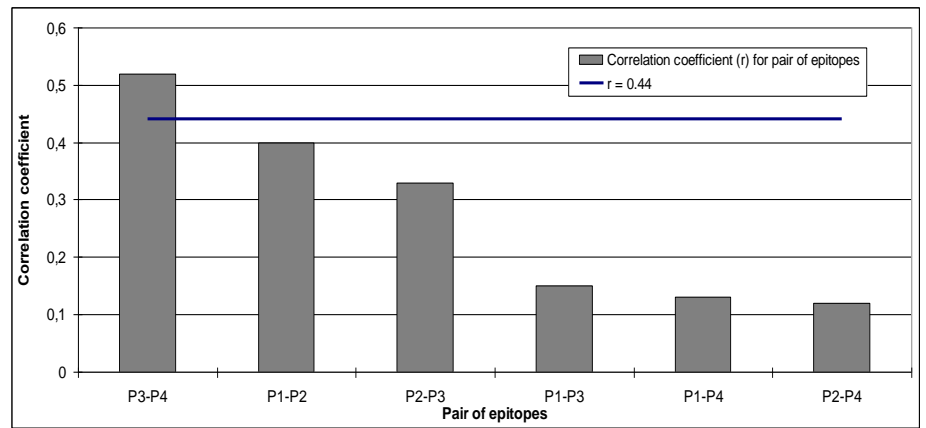

Figure 3 Comparison of correlation coefficients between different anti-PSA mAbs epitopes

\section{CONCLUSION}

Using the two inbred mice strains (NZB and Balb/c), an original set of 17 clones of the hybridomas - producers of high-affinity and specific anti-PSA mAbs was obtained. The biological properties of antibodies were studied including its specificity, affinity constant and titer in the culture fluid, as well as comparative epitope characteristic. It was established that the activity in ELISA, the affinity constant and titer in the culture liquid of the mAbs obtained from NZB mice are higher compared to the mAbs obtained from the splenocytes of Balb/c mice. It is proved that the Friguet' and Scatchard' methods for determining the antibodies affinity are comparable in determining the affinity constants of anti-PSA mAbs. It was shown that the obtained mAbs are directed to 4 epitopes of the PSA molecule: $2 \mathrm{mAbs}$, interacting with one of the epitopes, showed cross-activity with the related protein $\mathrm{hK} 2 ; 2 \mathrm{mAbs}$ of the same epitope specificity blocked the PSA enzymatic activity; and the mAbs of the other two epitopes either did not affect the PSA chymotrypsin activity at all, or this inhibitory effect was negligible.

The obtained mAbs recognize antigenic determinants that are not screened when PSA interacting with the ACT, as well as those that are located in the places where the PSA interacts with the ACT. Among these groups of antibodies are those that belong to different epitopes, which creates good prospects for further use of the obtained mAbs in immunoassay and immunobiotechnology, in particular, for the development of ELISA for quantitative determination of free and total PSA in human serum, as well as development of immunoaffinity sorbents for excretion of PSA and its complexes from biological fluids of the human body.

\section{REFERENCES}

BAYAT, A.A., GHODS, R., SHABANI, M., MAHMOUDI, A.R., YEGANEH, O., HASSANNIA, H., SADEGHITABAR, A., BALAY-GOLI, L., NOUTASHHAGHIGHAT, F., SARRAFZADEH, A.R., JEDDI-TEHRANI, M. 2015 Production and characterization of monoclonal antibodies against human prostate specific antigen. Avicenna Journal of Medical Biotechnology, 7(1), 2-7.

BOBROVNIK, S.A., DEMCHENKO, M.A., KOMISARENKO, S.V. 2010 Effect of poly reactive serum immunoglobulins to determine the affinity of serum antibodies. Ukrainian Biochemical Journal, 82(1), 66-69.

DUSKOVA, K., VESELY, S. 2015. Prostate specific antigen. Current clinical application and future prospects. Biomedical papers of the Medical Faculty of the University Palacky, Olomouc, Czechoslovakia, 159(1), 18-26. http://dx.doi.org/10.5507/bp.2014.046

FLETCHER, R.H. 2019. Guideline: Experts recommend against prostate cancer screening with prostate-specific antigen test. Annals of Internal Medicine, 170(2), JC2. http://dx.doi.org/10.7326/acpjc-2019-170-2-002

FRIGUET, B., CHAFFOTE, A., DJAVADI-OHANIANCE, L. 1985. Measurements of the true affinity constant in solution of antigen-antibody complexes by enzyme-linked immunosorbent assay. Journal of Immunological Methods, 77(2), 305-319. http://dx.doi.org/10.1016/0022-1759(85)90044-4 GALKIN, O.Y., KOMAR, A.G., BESARAB, O.B. 2019. Different mice inbred strains humoral immune response against human prostate-specific antigen.

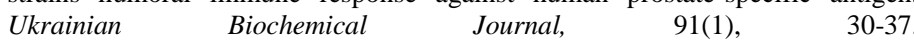
https://dx.doi.org/10.15407/ubj91.01.030

GALKIN, O.Y., SAVCHENKO, A.A., NIKITINA, K.I., DUGAN, O.M. 2013 Obtaining and study of properties of new monoclonal antibodies against human IgE. Ukrainian Biochemical Journal, 85(5), 81-87. http://dx.doi.org/10.15407/ubj85.05.081

GALKIN, O.YU., GORSHUNOV, YU.V., BESARAB, O.B., IVANOVA, O.M. 2018. Development and characterization of highly informative ELISA for the detection of $\mathrm{IgG}$ and IgA antibodies to Chlamydia trachomatis. Ukrainian Biochemical Journal, 90(3), 70-83. http://dx.doi.org/10.15407/ubj90.03.070 GODING, J. 1996. Monoclonal Antibodies: Principles and Practice. San Diego Academic Press, 492 p. ISBN 9780122870231
HAYTHORN, M.R., ABLIN, R.J. 2011. Prostate-specific antigen testing across the spectrum of prostate cancer. Biomarkers in Medicine, 5(4), 515-526. http://dx.doi.org/10.2217/bmm.11.53

CHRISTENSSON, A., LAURELL, C.B., LILJA, H. 1990. Enzymatic activity of prostatespecific antigen and its reactions with extracellular serine proteinase inhibitors. European Journal of Biochemistry, 194(3), 755-763. http://dx.doi.org/10.1111/j.1432-1033.1990.tb19466.x

KIM, B., DIKOVA, E., SHELLER, U. 1990. Evaluation of dissociation of antigen-antibody complexes by ELISA. Journal of Immunological Methods, 131(2), 213-222. http://dx.doi.org/10.1016/0022-1759(90)90192-X

KOHLER, G., MILSTEIN, C. 1975. Continuous cultures of fused cells secreting antibody of predefined specificity. Nature, 256, 495-497.

LANE, D., KOPROWSKI, H. 1982. Molecular recognition and the future of monoclonal antibodies. Nature, 296, 200-202.

LEINONEN, J., WU, P., STENMAN, U.H. 2002. Epitope mapping of antibodies against prostate-specific antigen with use of peptide libraries. Clinical Chemistry, 48(12), 2208-2216.

LOEB, S., CATALONA, W.J. 2007. Prostate-specific antigen in clinical practice. Cancer Letters, 249(1), 30-39. http://dx.doi.org/10.1016/j.canlet.2006.12.022

LUNDWALL, A., LILJA, H. 1987. Molecular cloning of human prostate specific antigen cDNA. FEBS Letters, 214(2), 317-322.

MÉNEZ, R., MICHEL, S., MULLER, B.H., BOSSUS, M., DUCANCEL, F. JOLIVET-REYNAUD, C., STURA, E.A. 2008. Crystal structure of a ternary complex between human prostate-specific antigen, its substrate acyl intermediate and an activating antibody. Journal of Molecular Biology, 376(4), 1021-1033. http://dx.doi.org/10.1016/j.jmb.2007.11.052

MICHEL, S., DELÉAGE, G., CHARRIER, J.P., PASSAGOT, J., BATTAILPOIROT, N., SIBAI, G., JOLIVET, M., JOLIVET-REYNAUD, C. 1999. Antifree prostate-specific antigen monoclonal antibody epitopes defined by mimotopes and molecular modeling. Clinical Chemistry, 45(5), 638-650.

NIKOLAENKO, I.V., GALKIN, AI.U., RAEVSKAIA, G.E., KAS'IANENKO, T.V., TERESHCHENKO, M.I., DONSKAIA E.S., SPIVAK, N.IA. 2005 Preparation of monoclonal antibodies to the Fc-fragment of human IgG and the use of their based immunoenzyme conjugates. Clinical Laboratory Diagnosis, $11,8-11$.

NURMIKKO, P., VÄISÄNEN, V., PIIRONEN, T., LINDGREN, S., LILJA, H., PETTERSSON, K. 2000. Production and characterization of novel anti-prostatespecific antigen (PSA) monoclonal antibodies that do not detect internally cleaved Lys145-Lys146 inactive PSA. Clinical Chemistry, 46(10), 1610-1618. PIIRONEN, T., VILLOUTREIX, B.O., BECKER, C., HOLLINGSWORTH, K. VIHINEN, M., BRIDON, D., QIU, X., RAPP, J., DOWELL, B., LÖVGREN, T., PETTERSSON, K., LILJA, H. 1998. Determination and analysis of antigenic epitopes of prostate specific antigen (PSA) and human glandular kallikrein2 (hK2) using synthetic peptides and computer modeling. Protein Science, 7, 259 269. http://dx.doi.org/10.1002/pro.5560070205

POKROVSKY, V.S., KAZANOV, M.D., DYAKOV, I.N., POKROVSKAYA, M.V., ALEKSANDROVA, S.S. 2016. Comparative immunogenicity and structural analysis of epitopes of different bacterial L-asparaginases. BMC Cancer, 16, 89. http://dx.doi.org/10.1186/s12885-016-2125-4

SCATCHARD, G. 1949. The attractions of proteins for small molecules and ions. Annals of the New York Academy of Sciences, 51, 660-672. http://dx.doi.org/10.1111/j.1749-6632.1949.tb27297.x

SHIROBOKOV, V.P., KOPANITSA, L.V., NIKOLAENKO, I.V. LIPATNIKOVA, K.I., SOLOGUB, V.K. 2001. Monoclonal antibodies used to differentiate between poliovirus types 1 and 3. Microbiological Journal (Ukraine), 63(6): 42-52.

SHTAPENKO, O.V., HEVKAN, I.I., SLYVCHUK, Y.I., SYRVATKA, V.Y., MATVIENKO, N.M. 2018. Formation and properties of polymer nanolayers to enhance cell growth in vitro. Innovative Biosystems and Bioengineering, 2(2), 105-109. http://dx.doi.org/10.20535/ibb.2018.2.2.132515

SCHEDLICH, L.J., BENNETTS, B.H., MORRIS, B.J. 1987. Primary structure of a human glandular kallikrein gene. DNA, 6(5), 429-437. http://dx.doi.org/10.1089/dna.1987.6.429

SYDYAKINA, YA.V., SIVAKOVA, A.A., KOMAR, A.G., GALKIN, A.YU. 2019. Prostat-specific antigen: biochemical, molecular-biological, and analytica aspects. Innovative Biosystems \& Bioengineering, 3(2), 86-95. http://dx.doi.org/10.20535/ibb.2019.3.2.164790 